\title{
Low-Intensity Ultrasound as a Novel Strategy to Improve the Cytotoxic Effect of Oncolytic Reovirus on Colorectal Cancer Model Cells
}

\author{
Negar Sharifi ${ }^{a} \quad$ Hoorieh Soleimanjahi $^{\mathrm{a}}$ Manijeh Mokhtari-Dizaji ${ }^{\mathrm{b}}$ \\ Razieh Sadat Banijamalia Maliheh Elhamipour ${ }^{a}$ Hesam Karimi ${ }^{a}$ c \\ ${ }^{a}$ Department of Virology, Faculty of Medical Sciences, Tarbiat Modares University, Tehran, Iran; ${ }^{b}$ Department of \\ Medical Physics, Faculty of Medical Sciences, Tarbiat Modares University, Tehran, Iran; 'Department of Hepatitis and \\ AIDS, Pasteur Institute of Iran, Tehran, Iran
}

\section{Keywords}

Colorectal cancer model cells - Oncolytic reovirus T3D .

Low-intensity ultrasound

\begin{abstract}
Background: Colorectal cancer is the third most common cancer all over the world, so in the battle to fight this hurdle, new therapeutic approaches such as oncolytic viruses (OV) have attracted much attention because of the fact that they can inherently kill cancer cells. Oncolytic reovirus is one of the candidates for treatment as a nonpathogenic species specially reovirus type 3 Dearing (T3D), which can induce apoptosis. To speed up the entry and function of the reovirus, low-intensity ultrasound, which is a safe system for damage to the cells and tissues, is a promising approach to be used in combination with other therapeutic approach. Methods: L929 and CT26 cells were infected with reovirus T3D and were exposed to ultrasonic irradiation $\left(1 \mathrm{MHz}, 1 \mathrm{~W} / \mathrm{cm}^{2}\right.$, and $20 \%$ duty factor) for $10 \mathrm{~s}$. The viruses' titer level of both groups was calculated in 2 types of cells by using the CCID method and compared with each other. Apoptosis, after 24 h, was measured by the flow cytometry method. Result: The results of $C C D_{50}$ in infected cells were exposed to low-inten-
\end{abstract}

karger@karger.com www.karger.com/int

Karger $\stackrel{\text { ' }}{5}$

GOPEN ACCESS
(C) 2021 The Author(s)

Published by S. Karger AG, Basel

This is an Open Access article licensed under the Creative Commons Attribution-NonCommercial-4.0 International License (CC BY-NC) (http://www.karger.com/Services/OpenAccessLicense), applicable to the online version of the article only. Usage and distribution for commercial purposes requires written permission. sity ultrasound showed an increased virus titer compared with unexposed infected cells. Moreover, according to the results of the flow cytometry test, it was found that the amount of apoptosis in infected cells that are exposed to low-intensity ultrasound waves is higher than those infected cells. Conclusion: Due to the results of $\mathrm{CCID}_{50}$ and flow cytometry tests, low-intensity ultrasound increases the cytotoxicity level of reovirus in $\mathrm{CT} 26$ cells of the cellular colorectal cancer model.

(c) 2021 The Author(s)

Published by S. Karger AG, Basel

\section{Introduction}

Cancer is a lethal problem globally, which was reported by the World Health Organization as the second leading cause of death after cardiovascular diseases [1]. Colorectal cancer is one of the major types of cancer that is classified as the third malignancy in the world [2]. Some popular methods of treating cancer include surgery, radiation, chemotherapy, etc.; besides, in some cases, the combination of stated methods is used in cancer therapeutics. Nevertheless, recurrent and metastatic diseases respond poorly to common therapies and have numerous 
side effects. For example, abnormal DNA methylation causes the tumor cells to be developed and processed [3]; therefore, alternative treatments with high potency and the least side effects are needed to significantly change the overall survival of cancer patients [4-6]. Nowadays, a variety of novel adjuvant therapies, particularly oncolytic viruses (OV), have been developed, which are attractive and promising strategies for cancer treatment [6-8].

Natural or engineered OV by lysing cells, destruction of tumor vessels, and induction of antitumor immunity can efficiently and precisely affect and eliminate cancer cells $[6,9]$. OV have a weak pathogenic effect on the normal cells, and compared with traditional drugs that reduce their effectiveness over time, the viruses' doses increase in the tumor by propagation [10].

Reovirus is a double-stranded RNA virus that was developed as one of the candidates for cancer treatment [11-14]. This virus specifically targets cancer cells with an activated Ras signaling pathway; accordingly, KRAS mutations are present in up to $40 \%$ of colorectal cancer cases [15-17]. Ras activation enhances viral uncoating and disassembly, raises the production of viral progeny with augmented infection, and animates the release of progeny through promoted apoptosis [18]. These features are the main therapeutic indices for viruses but are important issues in this type of remedy: if viral particles are unprotected in the bloodstream, they are quickly neutralized by the host's immune system, so they cannot reach the cancerous cells [19-21].

Since the 1940s, ultrasonic energy, which has a frequency of up to $20 \mathrm{kHz}$, has been used for imaging and remedial goals. Thermal effects with high-intensity and nonthermal effects with low intensity are 2 kinds of effects being composed depending on the energy delivered by ultrasound [22-25]. In preceding decades, the low-level intensity of ultrasound is being investigated for delivery of drugs, genes, viruses, and so on. Moreover, it plays a major role in elaborating the influence of the agent treatments $[6,26,27]$. Sonoporation is an effect of the lowlevel intensity of ultrasound, which increases the permeability of cell membranes in the presence of ultrasound waves [28]. This nonthermal mechanism of ultrasonic waves, especially the phenomenon of unstable cavitation, causes the production of cavities in the radiation environment, and their destruction in the vicinity of the cell membrane causes changes and ultimately increases the permeability of the cell membrane to environmental factors. This mechanism is reversible; in other words, the membrane returns to baseline by removing the radiation from the ultrasound $[26,29-33]$.

Oncolytic Effect of Reovirus with

Low-Intensity of Ultrasound
According to the previous published data, antibodies can neutralize the replication of viruses by blocking attachment to the host cell, preventing the penetration of the host cell membrane, or interfering with uncoating of the virus within the cells, so these viruses need help to conquer and fight limiting factors. It should be supported by increasing the cell permeability or enhance the migration capacity of reovirus to tumor site by application of mesenchymal stem cells for delivery of oncolytic reovirus in vitro. Using these strategies could open up new windows to combined therapy to achieve the excellent outcome in fighting to cancers [34].

Needless to say, by increasing the cell permeability, oncolytic effectiveness of reovirus might be enhanced before antibody production by promoting its entry, so more reoviruses can infect target cells; furthermore, based on the effect of increasing cell permeability by the low-level intensity of ultrasound, known as a safe way, the goal of this study was to investigate the effect of these waves as a way to raise the number of the oncolytic reoviruses entering our target cells.

\section{Materials and Methods}

\section{Cell Culture and Virus Seed Preparation}

Murine L929 fibroblasts cells were obtained from Tarbiat Modares University, as host cells for reovirus culture and control cells group, and murine colon carcinoma (CT26) were gained from pastor institute of Iran, as a colorectal cancer model's cells, cultured in Dulbecco's Modified Eagle's Medium (Gibco, NY, USA), containing $10 \%$ heat-inactivated fetal bovine serum (Gibco, NY, USA), $1 \%$ penicillin/streptomycin (Gibco, NY, USA), and grown in an incubator at $37^{\circ} \mathrm{C}$ in a humidified atmosphere with $5 \% \mathrm{CO}_{2}$ [35].

The reovirus type 3 Dearing (T3D), obtained from Dr. ShamsiShahrabadi (Iran University of Medical Sciences, Iran), was grown in semiconfluent L929 cells' monolayers in a $75-\mathrm{cm}^{2}$ flask with MOI 0.1 for virus seed preparation. Infected cells, incubated for 1 $\mathrm{h}$ at $37^{\circ} \mathrm{C}$, were washed with phosphate-buffered saline and again incubated in a new medium until the virus cytopathic effects appeared. Then, they were subjected to 2 cycles of freezing and thawing and followed by centrifugation. The supernatants, containing produced reovirus $\mathrm{T} 3 \mathrm{D}$, at first, were purified, and then, virus titration was measured by cell culture infection dose $50\left(\mathrm{CCID}_{50}\right)$. Eventually, they were kept at $-70^{\circ} \mathrm{C}$ until use [36].

\section{Ultrasound Irradiation}

After we made sure that low-intensity ultrasound has no adverse effect on the virus seed (by calculating the before and after virus titers and comparing them with each other) and based on the findings of preceding studies, murine L929 fibroblast cells as a control and CT26 as target cells were grown in enclosed sterile $3 \mathrm{~cm}$ polystyrene plates, and when these cells had got $80 \%$ confluency infected by viruses at MOI of 1 for considering safety issue 

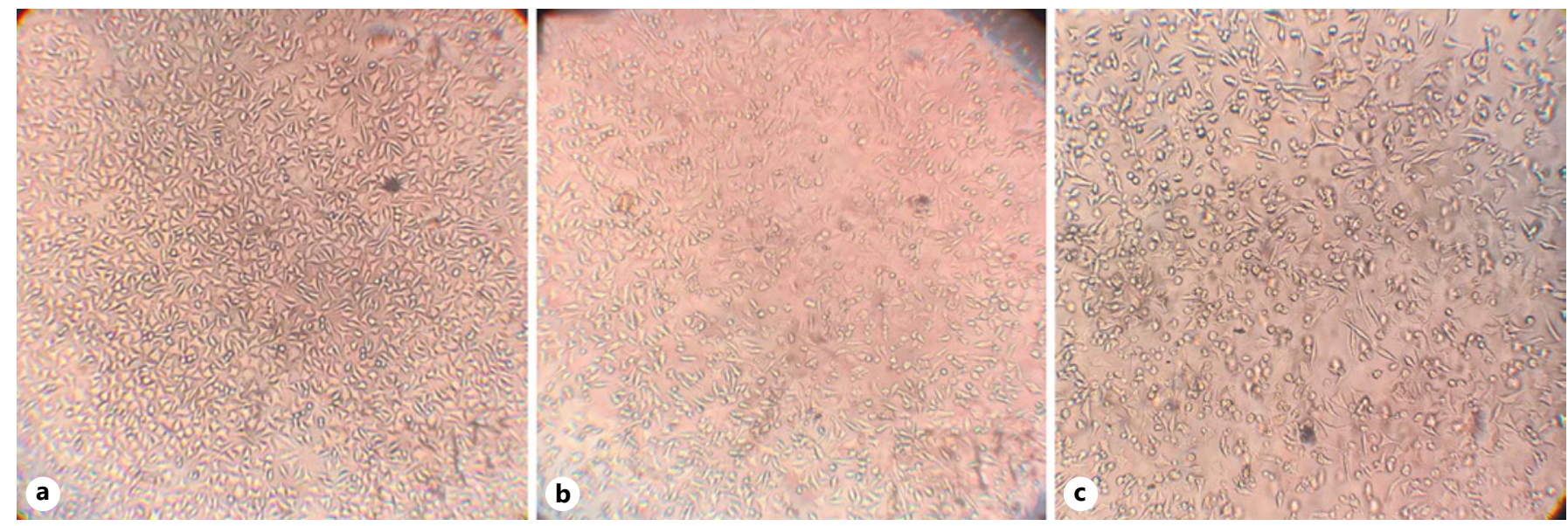

Fig. 1. Image of L929 cells infected with reovirus at MOI of 1 (titer 106) exposed and not exposed to low-intensity ultrasound under light microscopy after $24 \mathrm{~h}$, magnification $\times 10$. L929 cells control cells (a); L929 cells infected with reovirus at MOI of 1 after $24 \mathrm{~h}$

(b). c L929 cells infected with reovirus at MOI of 1 exposed to ultrasound. As shown in the figure of each group, the difference between them is completely obvious. To be more specific, $\mathbf{c}$ has more $\mathrm{CPE}$ than $\mathbf{b}$, and in $\mathbf{a}$ no $\mathrm{CPE}$ is seen.
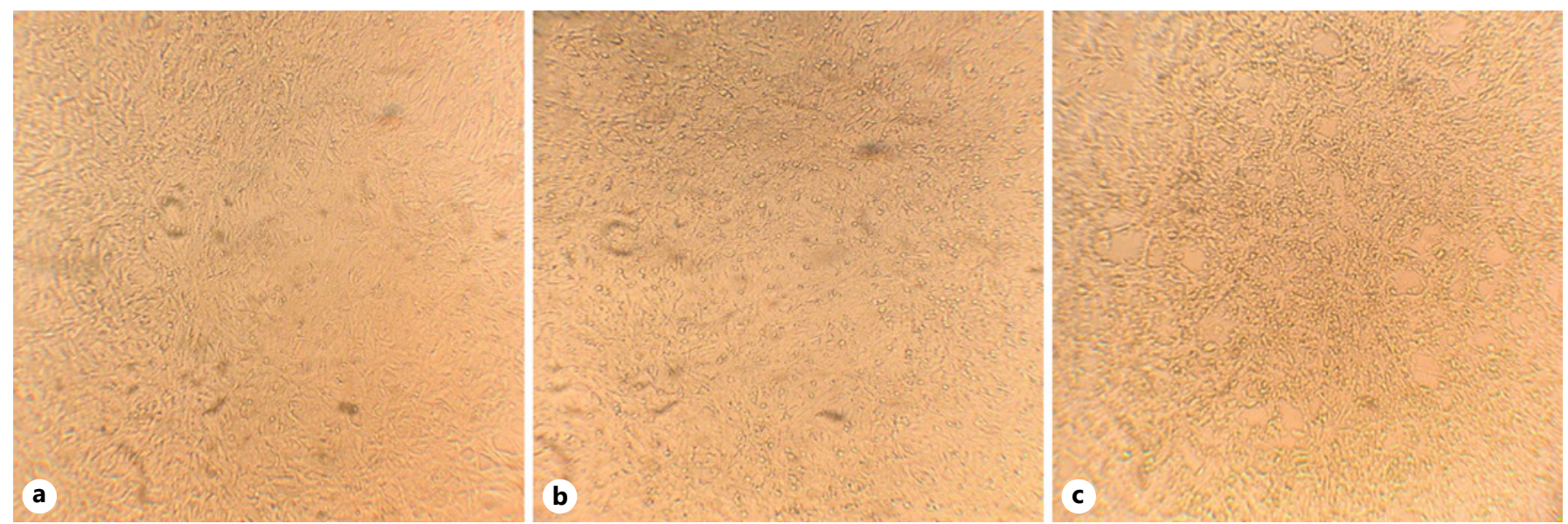

Fig. 2. Image of CT26 cells infected with reovirus at MOI of 1 (titer $10^{6}$ ) exposed and not exposed to low-intensity ultrasound under light microscopy after $24 \mathrm{~h}$, magnification $\times 10$. CT2 6 cells control cells (a); CT26 cells infected with reovirus at MOI of 1 after $24 \mathrm{~h}$

and because of the fact that reproduction of the virus is enough for observing the effect of ultrasound waves [37]. After an adsorption period of $30 \mathrm{~min}$, unabsorbed viruses were removed by rinsing the cell with phosphate-buffered saline to remove any unbound virus. Besides, they were covered with the Dulbecco's Modified Eagle's Medium. The dishes were held by a permanent holder whose bottom was at the distance of $2 \mathrm{~cm}$ from the probe and that distance was filled with coupling gel. The plates were exposed to ultrasound using an ultrasound machine (PhysiomedExpert, Germany), at room temperature. The ultrasound frequency was $1 \mathrm{MHz}$ during the experiments, and it was adjusted

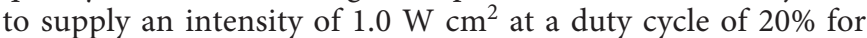
$10 \mathrm{~s}[38,39]$. (b). c CT26 cells infected with reovirus at MOI of 1 exposed to ultrasound. There is no $\mathrm{CPE}$ in $\mathbf{a}$, and $\mathrm{CPE}$ in $\mathbf{c}$ is much more in contrast to $\mathbf{b}$.

\section{Determination of Virus Titer by CCID $_{50}$}

When the first development of CPE had been observed (approximately $18 \mathrm{~h}$ after infection with the viruses, CPE can follow by a light microscope [37]), L929 and CT26 cells and their supernatants were collected individually, and then the cells were frozen and thawed twice and were centrifuged. Next, both cell lysates and their supernatant were collected and evaluated by CCID $_{50}$ on L929 cells. The monolayers of L929 cells in 96-wells plates were inoculated with a collected sample of a 10 -fold serially dilution of each group. Inoculated cells were incubated at $37^{\circ} \mathrm{C}$ in a humidified atmosphere with $5 \% \mathrm{CO}_{2}$ for approximately $72 \mathrm{~h}$. CPE consequences examined by comparing with the positive and negative controls columns on 96 plates. Virus titers were determined according to 
Table 1. Reovirus titers in different groups were calculated after infection, according to the Reed \& Munch formula. Data are expressed as the mean \pm SD of 3 independent experiments

\begin{tabular}{lllll}
\hline Groups & L929 & L929 + US & CT26 & CT26 + US \\
\hline Virus titer & $10^{5.166}$ & $10^{5.749}$ & $10^{3.499}$ & $10^{4.499}$ \\
\hline
\end{tabular}

the Reed \& Muench formula. $\log _{10} 50 \%$ end point dilution $=\log _{10}$ of dilution showing mortality next above $50 \%$ - (difference of logarithms $\times$ logarithm of dilution factor) [37].

Evaluation of Apoptosis by Flow Cytometry Technique

The cell death was analyzed by the flow cytometry technique. First, L929 and CT26 cells were cultured at $3 \mathrm{~cm}$ plates and then were infected with reovirus at MOI of 1 . After $30 \mathrm{~min}$, infected cells were exposed to ultrasounds for $1 \mathrm{~min}$. When CPE was observed, cells were harvested and analyzed with the Annexin $\mathrm{V}$ apoptosis detection kit FITC (eBioscience, USA, according to the manufacturer's instructions) and a FACSCanto II flow cytometer (BD Biosciences, NJ, USA) [40]. We chose exactly after CPE appearance for evaluating apoptosis, owing to previous research because the cells die more over time due to the increase in the amount of viruses, neither can we see the effect of the waves on the increased reovirus entry nor we can analyze the impact of the ultrasound on viruses, cytotoxicity.

\section{Statistical Analysis}

All the experiments in this research were performed 3 times in 3 replicates. Data were expressed as mean \pm SD. One-way ANOVA and 2-way ANOVA with Tukey's test were performed for data comparisons. The GraphPad Prism software version 7.04 was used to plot charts. Asterisks indicated that groups are significantly different from each other $\left({ }^{*} p \leq 0.05 ;{ }^{* *} p \leq 0.01 ;{ }^{* * *} p \leq 0.001\right.$; $* * * * p \leq 0.0001)$.

\section{Results}

\section{Enhancement of Oncolytic Activity of Reovirus by}

\section{Low-Intensity Ultrasound}

Approximately $18 \mathrm{~h}$ after the test, involving infection with Reo T3D and then exposure to low-intensity of ultrasound, CPEs were shown under an inverted microscope, and then up to $72 \mathrm{~h}$ ' postinfection, virus titers of all groups were calculated based on the Reed \& Munch formula (shown in Fig. 1, 2; Table 1). The increase in the cytopathic effect of infected cells that are exposed to ultrasound is quite evident in comparison with control cells (shown in Fig. 3), and the virus's titers were significantly increased in target cells' groups that were exposed to ultrasound. The virus titer in L929 cells that were exposed to ultrasound exceeded $0.5 \mathrm{Log}$, and the virus titer in CT26 cells that were exposed to ultrasound's waves exceeded 1.0 Log compared to their control.

Oncolytic Effect of Reovirus with

Low-Intensity of Ultrasound

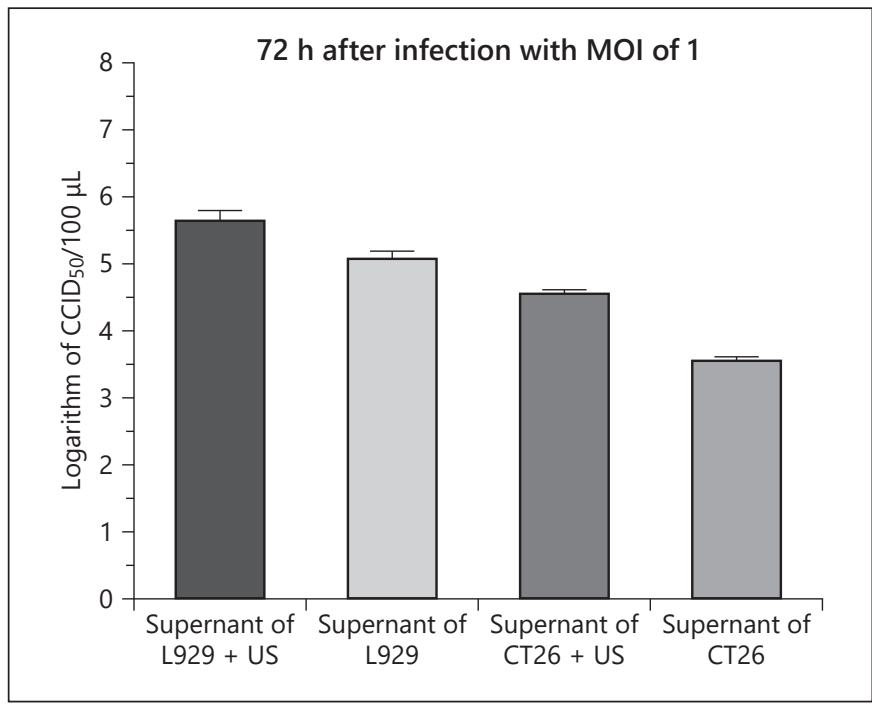

Fig. 3. The rate of reovirus titer on L929 cells and CT26 cells up to72 h of infection with MOI of 1 . The outcomes were represented as a logarithm of copies $/ \mathrm{mL}$. The results show the cells that are exposed to low-intensity ultrasound about 0.5 to $1 \log$ increased in reovirus titers. In other words, virus entry is much more efficient when used with low-intensity ultrasound.

\section{Remarkable Apoptosis Induction of Reovirus with Low-Intensity Ultrasound}

The cell death percentage through apoptosis in 4 different groups of L929 (as a control) and 4 different groups of CT26 was measured, after $24 \mathrm{~h}$, by using the AnnexinPI technique (Invitrogen) with flow cytometry (displayed in Fig. 4, 5; Table 2). As shown in Fig. 6, the results demonstrated that the rate of apoptosis remarkably increased, about 1.5 times more, in the groups exposed to ultrasound compared to the control groups not exposed to ultrasound waves. Furthermore, the rate of apoptosis in different cells is not the same. In other words, the cell death through apoptosis, by reovirus, in each cell depends on the type of cell. In addition, ultrasound waves can induce apoptosis alone in CT26 cells, as cancer cells, although it does not have a serious adverse effect on L929, which is a normal and control cell.

\section{Discussion}

Given the increased prevalence of colorectal cancer, and its poor response to current treatments, targeted therapeutic approaches are required [41]. OVs have the ability to selectively replicate in cancer cells and exhibit antitumor effects using a variety of mechanisms; further- 


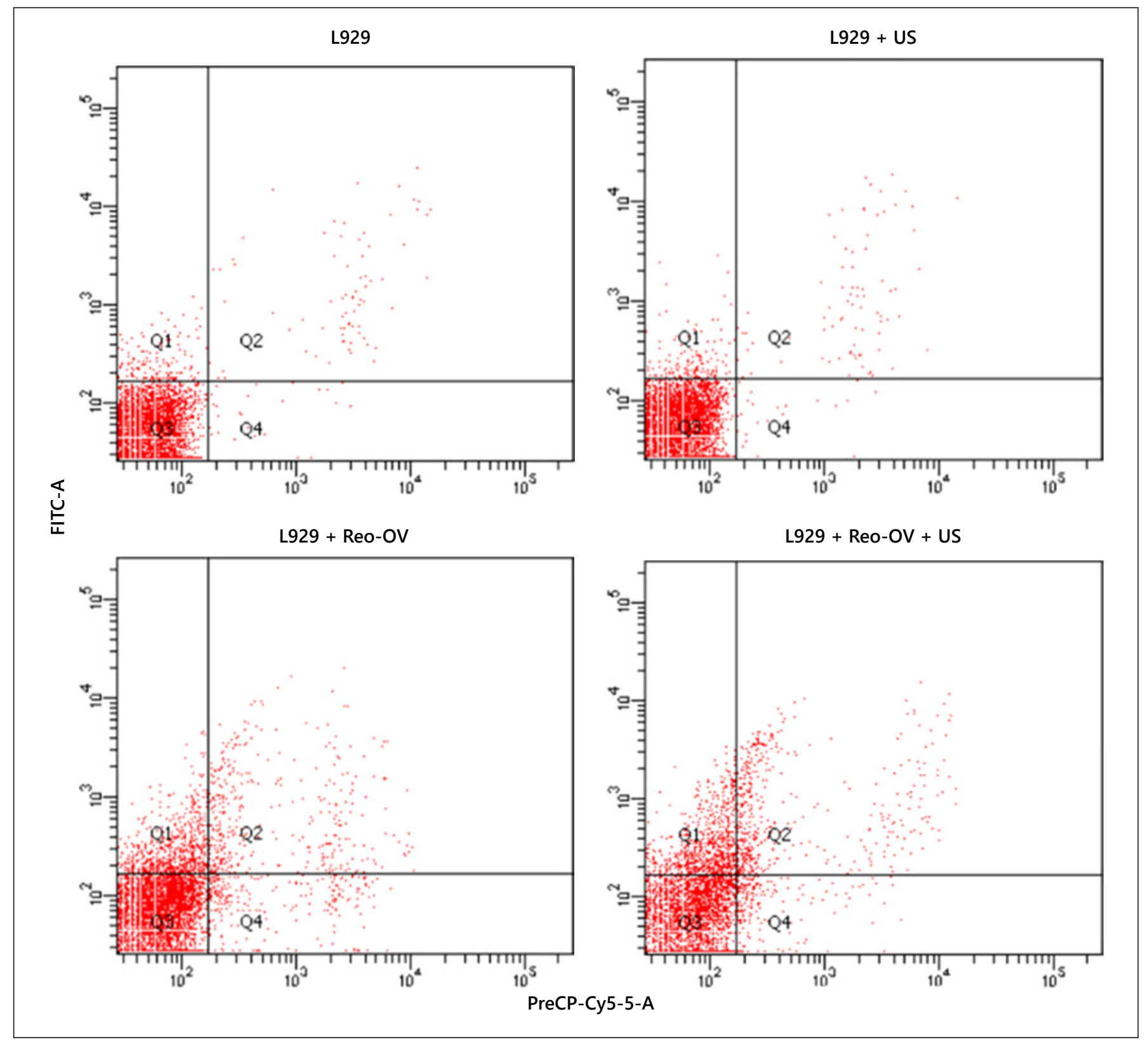

Fig. 4. Spot chart showing apoptosis induced by reovirus at MOI of 1 in the studied groups of L929 cells after $24 \mathrm{~h}$ of infection and exposure to low-intensity ultrasound. Annexin V vertical axis and PI horizontal axis: Q1 primary apoptosis, Q2 secondary apoptosis, Q3 living cells, and Q4 necrosis. OV, oncolytic viruses.

more, many engineered viruses are undergoing different phases of clinical trials; for example, a specific form of herpes simplex virus for the treatment of melanoma has been approved by the US Food and Drug Administration [42]. Oncolytic reovirus is one of the most attractive anticancer agents for clinical trial $[43,44]$. As a case in point, Smakman and colleagues concluded that reovirus serotype T3D is an effective therapeutic agent in the treatment of CT26 metastasis [45]; as it came from our flow cytometry results, it is clear that reovirus was capable of killing CRC cells well.

The major mechanism of oncolytic reovirus is the ability for inducing apoptosis. Thirukkumaran and colleagues concluded that reovirus induced apoptosis in breast cancer via the NF-KB pathway [46]. In addition, Cho and colleagues demonstrated the ability of the reovi- 


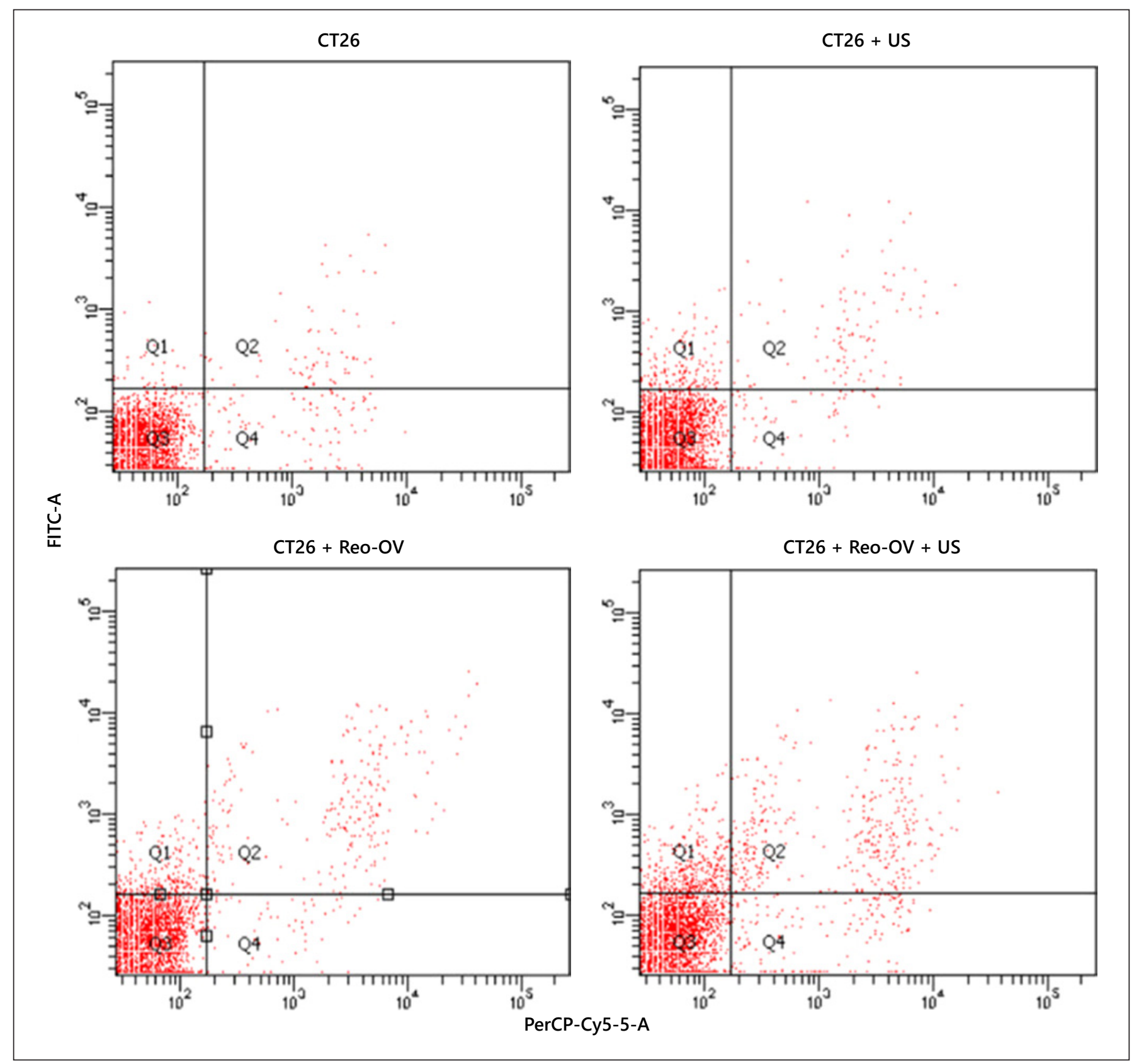

Fig. 5. Spot diagram of the apoptosis induction induced by reovirus at MOI of 1 in the studied groups of CT26 cells after $24 \mathrm{~h}$ of infection and exposure to low-intensity ultrasound. Annexin V vertical axis and PI horizontal axis: Q1 primary apoptosis, Q2 secondary apoptosis, Q3 living cells, and Q4 necrosis. OV, oncolytic viruses.

rus to induce apoptosis to resistant gastric cancer cells by TRAIL [47]. As a potential outcome of this project, oncolytic reovirus T3D at MOI of 1 induced apoptosis in CT26 cells.

The most momentous issue during the use of $\mathrm{OV}$ is neutralized by the specific antibody in the body, which causes that viruses cannot reach their targets alone; thus, virus delivery is the major concern for this method [7]. To overcome this hurdle, combination therapy was proposed [8]. One way is using ultrasound as a new approach is proposed, which has previously been used in various topics such as drug and DNA molecule release, gene transfer, gene expression, and various other applications because of its low invasiveness $[48,49]$. Baghbani and her 
Table 2. The rate of apoptosis in different groups

\begin{tabular}{lllllllll}
\hline Group & L929 & L929+ US & L929+reo & L929+reo + US & CT26 & CT26 + US & CT26 + reo & CT26 + reo + US \\
\hline Rate of apoptosis & 2.90 & 3.00 & 14.10 & 20.80 & 1.50 & 3.90 & 7.70 & 11.80 \\
\hline
\end{tabular}

team came to the conclusion that ultrasound has the potential for being as a drug delivery system, and they had seen the perfect anticancer effect of ultrasound with doxorubicin-loaded PFH nanodroplets in the breast cancer mice model [50]. In the studies of Okunaga and colleagues, low-intensity ultrasound increased the entry of HSV-1 into oral squamous cell carcinoma (SCC) and ultimately suppressed the growth of rat tumors [39]; besides, Shintani concluded that the exposure of ultrasound to Vero cells and oral SCC could accelerate the process of HSV-1 infection; in addition, ultrasound may be useful for increasing the efficiency of HSV-1 infection in viral therapy for SCC [38]. In recent years, researches have been conducted via application of ultrasound in the combination with OVs in the treatment of various types of cancers, but a study investigating the effects of low-intensity ultrasound and reovirus had not been performed on the CT26 cell as a sample of colorectal cancer. Consequently, the current study has considered the low-intensity ultrasound advantages, such as the availability of the device, the cheapness of the method, and the improved treatment efficacy due to the increased probability of cytotoxicity of the virus followed by the increase in the cell membrane permeability.

In the present study, low-intensity ultrasound was used to enhance the cytotoxicity of reovirus due to enhanced virus entry into the target cell. In addition, the behavior of L929 cells as a control and CT26 as a colorectal cancer model cells was investigated. First, we examined the sensitivity of cells to the ultrasound waves but found no apparent destruction after incubation for $24 \mathrm{~h}$. Then, the cells were infected with reovirus and were subjected to low-intensity ultrasound to investigate differences in virus titers compared to the control group. As the results show, the virus titers were significantly higher in the cells that are exposed to ultrasound than not exposed. Therefore, not only can ultrasound increase the rate of virus entry into the cells, which improved the virus titer, but also it can accelerate the process of reovirus infection. Moreover, reovirus shedding in exposure cells has increased meaningfully. It can also be noted that the virus titers in exposed and unexposed L929 cells to the ultrasound waves were higher than CT26 cells so that the effect

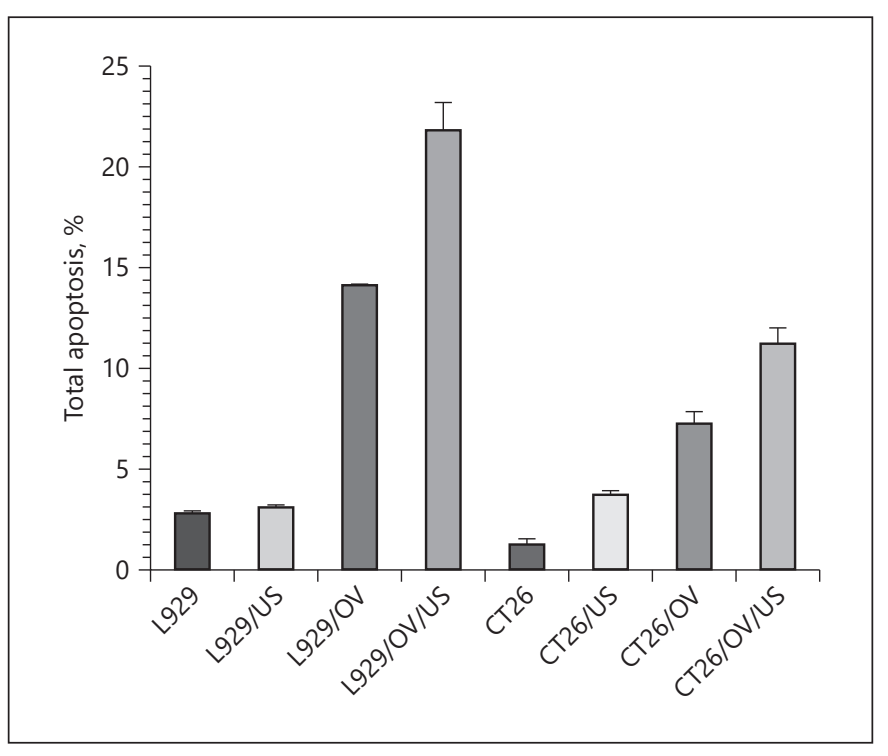

Fig. 6. The amount of total apoptosis in the experimental groups. In these groups after $24 \mathrm{~h}$ of virus inoculation and exposure to ultrasound waves, apoptosis was measured by the flow cytometry technique. The amount of apoptosis in groups infected with reo $\mathrm{T} 3 \mathrm{D}$ and exposed to ultrasound waves is greater than groups infected with reo T3D alone; besides, the rate of apoptosis in groups that are just exposed to ultrasound waves is little. In addition, the rate of apoptosis is higher in L929 than in CT26 owing to the fact that it is the original main host of reo T3D. The figure shows 1 representative result from 3 independent experiments. OV, oncolytic viruses.

of reovirus on various cells is different. Equally important, the L929 cell is the main host of the reovirus. Banijamali and colleagues had concluded that the cytopathic effect of reovirus T3D was seen in both L929 and ADMSCs cells, but 1 log reduction in virus titer and shedding in AD-MSCs was seen compared to L929 cells based on different characteristics of cells $[34,35]$.

According to the flow cytometry analysis, reovirus T3D is an effective therapeutic agent in the treatment of CT26 metastasis and has shown the ability to induce apoptosis in those cells. Likewise, the low-intensity ultrasound effect on the rate of reovirus cytotoxicity could accelerate the process of reovirus infection and these waves increased the rate of reovirus cytotoxicity in the cells un- 
derstudy as we mention above owing to an increase in virus entry. Increased apoptotic cell death in both exposed cells can result in the efficacy of treatment with OV to inhibit the progression of cancer cells and lead to the treatment of cavernous cells.

\section{Conclusion}

It can be concluded that using the combination of reovirus with low-intensity ultrasound on murine-derived cells could increase the oncolytic activity of reovirus and the rate of cell death. Increased cell death by apoptosis in L929 and CT26 cells can have positive results in the efficacy of treatment with oncolytic reovirus in vivo because by increasing the speed of virus entry into target cells in this preclinical experiment, it might efficiently prevent the effect of antibodies on the virus neutralization in the human body. In addition, although the outcome of this project illustrated a higher rate of cell death, future studies, using a combination of reovirus $\mathrm{T} 3 \mathrm{D}$ and low intensity of ultrasound, should be conducted to measure the factors that induce cell death more accurately by, for example, Western blot analysis for cytochrome c release, caspase 9, caspase 3 processing, and PARP cleavage; therefore, more studies are required to evaluate the efficacy of this method.

\section{Acknowledgments}

The results described in this manuscript were part of the student thesis, which was supported by the grant number med-75121 from the Research Deputy of Faculty of Medical Sciences at Tarbiat Modares University.

\section{Statement of Ethics}

According to the rules of Tarbiat Modares University, due to the fact that we used animal cells, so the paper is exempt from Ethical Committee Approval. The current study was approved that it does not need the ethical committee code of Tarbiat Modares University. In this study, written informed consent was not required.

\section{Conflict of Interest Statement}

The authors have no conflicts of interest to declare.

\section{Funding Sources}

This project was supported by Tarbiat Modares University's grant for Master students of medical virology.

\section{Author Contributions}

Negar Sharifi designed and carried out the experience, analyzed data, and wrote the manuscript. Hoorieh Soleimanjahi drafted and designed the experience and supervised the research. Manijeh Mokhtari-Dizaji supervised the research. Maliheh Elhamipour performed the experience. Razieh Sadat Banijamali performed the experience. Hesam Karimi performed the experience and cowrote the manuscript.

\section{Data Availability Statement}

All data generated or analyzed during this study are included in this article. Further enquiries can be directed to the corresponding author.

\section{References}

1 Global Burden of Disease Cancer Collaboration; Fitzmaurice C, Allen C, Barber RM, Barregard L, Bhutta ZA, et al. Global, regional, and national cancer incidence, mortality, years of life lost, years lived with disability, and disability-adjusted life-years for 32 cancer groups, 1990 to 2015: a systematic analysis for the global burden of Disease Study. JAMA Oncol. 2017;3(4):524-48.

2 Moamer S, Baghestani AR, Pourhoseingholi MA, Maboudi AAK, Agha SHS, Zali MR. Prognostic factors for survival in patients with colorectal cancer in Iran between 20042015: competing risks regression analysis with generalized Weibull model. Basic Clin Cancer Res. 2017;9(1).
3 Stomper J, Rotondo JC, Greve G, Lübbert M. Hypomethylating agents (HMA) for the treatment of acute myeloid leukemia and myelodysplastic syndromes: mechanisms of resistance and novel HMA-based therapies. Leukemia. 2021:1-17.

4 Matthay KK, Villablanca JG, Seeger RC, Stram DO, Harris RE, Ramsay NK, et al. Treatment of high-risk neuroblastoma with intensive chemotherapy, radiotherapy, autologous bone marrow transplantation, and 13-cis-retinoic acid. Children's Cancer Group. N Engl J Med. 1999;341(16):1165-73.

5 Cengiz BB, Asik MD, Kara G, Turk M, Denkbas EB. Therapeutic potential of inhibiting ABCE1 and eRF3 genes via siRNA strategy using chitosan nanoparticles in breast cancer cells. J Nanopart Res. 2015;17(4):168.

6 Nande R, Howard CM, Claudio PP. Ultrasound-mediated oncolytic virus delivery and uptake for increased therapeutic efficacy: state of art. Oncolytic Virother. 2015;4: 193.

7 Marchini A, Scott EM, Rommelaere J. Overcoming barriers in oncolytic virotherapy with HDAC inhibitors and immune checkpoint blockade. Viruses. 2016;8(1):9.

8 Babaei A, Soleimanjahi H, Soleimani M, Arefian $\mathrm{E}$. The synergistic anticancer effects of ReoT3D, CPT-11, and BBI608 on murine colorectal cancer cells. Daru. 2020;28(2):55565. 
9 Taguchi S, Fukuhara H, Homma Y, Todo T. Current status of clinical trials assessing oncolytic virus therapy for urological cancers. Int J Urol. 2017;24(5):342-51.

10 Meerani S, Yao Y. Oncolytic viruses in cancer therapy. Eur J Sci Res. 2010;40(1):156-71.

11 Kemp V, Hoeben RC, van den Wollenberg DJ. Exploring reovirus plasticity for improving its use as oncolytic virus. Viruses. 2015; $8(1): 4$.

12 Zhao X, Chester C, Rajasekaran N, He Z, Kohrt HE. Strategic combinations: the future of oncolytic virotherapy with reovirus. Mol Cancer Ther. 2016;15(5):767-73.

13 Le Boeuf F, Gebremeskel S, McMullen N, He $\mathrm{H}$, Greenshields AL, Hoskin DW, et al. Reovirus FAST protein enhances vesicular stomatitis virus oncolytic virotherapy in primary and metastatic tumor models. Mol Ther Oncolytics. 2017;6:80-9.

14 Banijamali RS, Soleimanjahi H, Soudi S, Kari$\mathrm{mi} \mathrm{H}$. The effect of oncolytic reovirus infection on nitric oxide secretion and induction of apoptosis in adipose tissue-derived mesenchymal stem cells. Iran J Med Microbiol. 2018;12(3):218-29.

15 Hirasawa K, Nishikawa SG, Norman KL, Alain T, Kossakowska A, Lee PW. Oncolytic reovirus against ovarian and colon cancer. Cancer Res. 2002;62(6):1696-701.

16 Gong J, Mita MM. Activated ras signaling pathways and reovirus oncolysis: an update on the mechanism of preferential reovirus replication in cancer cells. Front Oncol. 2014; 4:167.

17 Maitra R, Seetharam R, Tesfa L, Augustine TA, Klampfer L, Coffey MC, et al. Oncolytic reovirus preferentially induces apoptosis in KRAS mutant colorectal cancer cells, and synergizes with irinotecan. Oncotarget. 2014; 5(9):2807.

18 Phillips MB, Stuart JD, Rodríguez Stewart RM, Berry JT, Mainou BA, Boehme KW. Current understanding of reovirus oncolysis mechanisms. Oncolytic Virother. 2018;7:53.

19 Sahin E, Egger ME, McMasters KM, Zhou HS Development of oncolytic reovirus for cancer therapy. Jct. 2013;04(06):1100.

20 Kim J, Hall RR, Lesniak MS, Ahmed AU. Stem cell-based cell carrier for targeted oncolytic virotherapy: translational opportunity and open questions. Viruses. 2015;7(12):6200-17.

21 Moreno R, Rojas LA, Villellas FV, Soriano VC, García-Castro J, Fajardo CA, et al. Human menstrual blood-derived mesenchymal stem cells as potential cell carriers for oncolytic adenovirus. Stem Cells Int. 2017;2017: 3615729.

22 Hill CR, Bamber JC, ter Haar GR. Physical principles of medical ultrasonics: ASA; 2004.
23 Barati AH, Mokhtari-Dizaji M. Ultrasound dose fractionation in sonodynamic therapy. Ultrasound Med Biol. 2010;36(6):880-7.

24 Udroiu I. Ultrasonic drug delivery in Oncology. J BUON. 2015;20:381-90.

25 Yildirim A, Blum NT, Goodwin AP. Colloids, nanoparticles, and materials for imaging, delivery, ablation, and theranostics by focused ultrasound (FUS). Theranostics. 2019;9(9): 2572.

26 Vilhena NAP. Ultrasound assisted oncolytic virotherapy: in vitro and in vivo studies; 2015.

27 Chowdhury SM, Lee T, Willmann JK. Ultrasound-guided drug delivery in cancer. Ultrasonography. 2017;36(3):171.

28 Zhang L, Liu X, Gao L, Ji Y, Wang L, Zhang $\mathrm{C}$, et al. Activation of piezol by ultrasonic stimulation and its effect on the permeability of human umbilical vein endothelial cells. Biomed Pharmacother. 2020;131:110796.

29 Tang H, Wang CC, Blankschtein D, Langer R. An investigation of the role of cavitation in low-frequency ultrasound-mediated transdermal drug transport. Pharm Res. 2002; 19(8):1160-9.

30 Hernot S, Klibanov AL. Microbubbles in ultrasound-triggered drug and gene delivery. Adv Drug Deliv Rev. 2008;60(10):1153-66.

31 Ebrahiminia A, Mokhtari-Dizaji M, Toliyat T. Dual frequency cavitation event sensor with iodide dosimeter. Ultrason Sonochem. 2016;28:276-82.

32 Helfield B, Chen X, Watkins SC, Villanueva FS. Biophysical insight into mechanisms of sonoporation. Proc Natl Acad Sci U S A. 2016; 113(36):9983-8.

33 Man VH, Li MS, Derreumaux P, Wang J, Nguyen TT, Nangia S, et al. Molecular mechanism of ultrasound interaction with a blood brain barrier model. J Chem Phys. 2020; 153(4):045104.

34 Banijamali RS, Soleimanjahi H, Soudi S, Kari$\mathrm{mi} \mathrm{H}$. Mesenchymal stem cells support delivery and boost the efficacy of oncolytic reoviruses in TC-1 tumor cells. J Cell Biochem. 2021.

35 Banijamali RS, Soleimanjahi H, Soudi S, Karimi H, Abdoli A, Seyed Khorrami SM, et al. Kinetics of oncolytic reovirus T3D replication and growth pattern in mesenchymal stem cells. Cell J. 2020;22(3):283.

36 Babaei A, Bannazadeh Baghi H, Nezhadi A, Jamalpoor Z. In vitro anti-cancer activity of adipose-derived mesenchymal stem cells increased after infection with oncolytic reovirus. Adv Pharm Bull. 2021;11(2):361-70.

37 Banijamali RS, Soleimanjahi H, Soudi S, Kari$\mathrm{mi} \mathrm{H}$. The effect of oncolytic reovirus infection on nitric oxide secretion and induction of apoptosis in adipose tissue-derived mesenchymal stem cells. Iran J Med Microbiol. 2018;12(3):218-29.
38 Shintani M, Takahashi G, Hamada M, Okunaga S, Iwai S, Yura Y. Effect of ultrasound on herpes simplex virus infection in cell culture. Virol J. 2011;8(1):446.

39 Okunaga S, Takasu A, Meshii N, Imai T, Hamada M, Iwai S, et al. Ultrasound as a method to enhance antitumor ability of oncolytic herpes simplex virus for head and neck cancer. Cancer Gene Ther. 2015;22(3):163.

40 Rezazadeh A, Soleimanjahi H, Soudi S, Habibian A. Comparison of the effect of adipose mesenchymal stem cells-derived secretome with and without reovirus in CT26 cells. Archives of Razi Institute. 2021.

41 Li Z, Fan D, Xiong D. Mesenchymal stem cells as delivery vectors for anti-tumor therapy. Stem Cell Investig. 2015;2:6.

42 Ferhat M. Oncolytic viruses: the next major breakthrough in cancer treatment. Jhvrv. 2017;5(1):00141.

43 Rahal A, Musher B. Oncolytic viral therapy for pancreatic cancer. J Surg Oncol. 2017; 116(1):94-103.

44 Babaei A, Soleimanjahi H, Soleimani M, Arefian E. Mesenchymal stem cells loaded with oncolytic reovirus enhances antitumor activity in mice models of colorectal cancer. Biochem Pharmacol. 2021;190:114644.

45 Smakman N, van den Wollenberg DJ, Borel Rinkes IH, Hoeben RC, Kranenburg O. Sensitization to apoptosis underlies KrasD12-dependent oncolysis of murine C26 colorectal carcinoma cells by reovirus T3D. J Virol. 2005;79(23):14981-5.

46 Thirukkumaran C, Shi ZQ, Thirukkumaran P, Luider J, Kopciuk K, Spurrell J, et al. PUMA and NF-kB are cell signaling predictors of reovirus oncolysis of breast cancer. PloS one. 2017;12(1):e0168233.

47 Cho IR, Koh SS, Min HJ, Park EH, Srisuttee $\mathrm{R}$, Jhun $\mathrm{BH}$, et al. Reovirus infection induces apoptosis of TRAIL-resistant gastric cancer cells by down-regulation of Akt activation. Int J Oncol. 2010;36(4):1023-30.

48 Haber T, Baruch L, Machluf M. Ultrasoundmediated mesenchymal stem cells transfection as a targeted cancer therapy platform. Sci Rep. 2017;7:42046.

49 Myers R, Grundy M, Rowe C, Coviello CM, Bau L, Erbs P, et al. Ultrasound-mediated cavitation does not decrease the activity of small molecule, antibody or viral-based medicines. Int J Nanomedicine. 2018;13:337.

50 Baghbani F, Moztarzadeh F, Mohandesi JA Yazdian F, Mokhtari-Dizaji M. Novel alginate-stabilized doxorubicin-loaded nanodroplets for ultrasounic theranosis of breast cancer. Int J Biol Macromol. 2016;93:512-9. 